\title{
Protective effects of gallic acid against spinal cord injury-induced oxidative stress
}

\author{
YONG HONG YANG, ZAO WANG, JIE ZHENG and RAN WANG \\ Department of Orthopedics, The $117^{\text {th }}$ Hospital of People's Liberation Army, Hangzhou, Zhejiang 310013, P.R. China
}

Received May 4, 2014; Accepted February 26, 2015

DOI: $10.3892 / \mathrm{mmr} .2015 .3738$

\begin{abstract}
The present study aimed to investigate the role of gallic acid in oxidative stress induced during spinal cord injury (SCI). In order to measure oxidative stress, the levels of lipid peroxide, protein carbonyl, reactive oxygen species and nitrates/nitrites were determined. In addition, the antioxidant status during SCI injury and the protective role of gallic acid were investigated by determining glutathione levels as well as the activities of catalase, superoxide dismutase, glutathione peroxidase and glutathione-S-transferase. Adenosine triphophatase (ATPase) enzyme activities were determined to evaluate the role of gallic acid in SCI-induced deregulation of the activity of enzymes involved in ion homeostasis. The levels of inflammatory markers such as nuclear factor (NF) $-\kappa B$ and cycloxygenase (COX)-2 were determined by western blot analysis. Treatment with gallic acid was observed to significantly mitigate SCI-induced oxidative stress and the inflammatory response by reducing the oxidative stress, decreasing the expression of $\mathrm{NF}-\kappa \mathrm{B}$ and $\mathrm{COX}-2$ as well as increasing the antioxidant status of cells. In addition, gallic acid modulated the activity of ATPase enzymes. Thus the present study indicated that gallic acid may have a role as a potent antioxidant and anti-inflammatory agent against SCI.
\end{abstract}

\section{Introduction}

Spinal cord injury (SCI) occurs as a result of a multifactorial process, involving primary injury subsequently followed by secondary effects. Primary injury usually occurs due to mechanical trauma, whereas secondary injury occurs as a result of the primary injury; in addition, the severity of secondary injury is proportional to that of the primary mechanical damage (1). Secondary injury is characterized by apoptotic or necrotic events, however the predominant causes

Correspondence to: Mr. Ran Wang, Department of Orthopedics, The $117^{\text {th }}$ Hospital of People's Liberation Army, 14 Lingyin Road, Xihu, Hangzhou, Zhejiang 310013, P.R. China

E-mail: wrqj991@gmail.com

Key words: oxidative stress, antioxidant, inflammation, gallic acid, spinal cord-injury of such events are mediated through oxidative stress $(2,3)$. The central mediator in SCI injury is the generation of reactive oxygen species (ROS), which have various effects at the cellular level. Previous studies have suggested that the initial formation of ROS and reactive nitrogen species (RNS) molecules initiate lipid peroxidation and protein carbonylation (4). Lipid peroxidation results in the disorganization of phospholipids in membranes; in addition, the end products of lipid peroxidation damage the structure and function of proteins, thereby exacerbating oxidative stress conditions. In addition, various signaling events mediated through the deregulation of ion homeostasis contribute to oxidative stress and tissue damage (5). It has been widely reported and accepted that the end results of free radical-mediated oxidative stress and subsequent inflammatory mechanisms serve a key role in SCI. Oxidative stress and deregulation of ion homeostasis initiate and promote cellular damage; therefore, protection against these effects using pharmacological intervention may be an effective therapeutic strategy. Thus, the present study aimed to investigate the protective effects of gallic acid against SCI injury in the context of oxidative stress and ion homeostasis.

Gallic acid is a phenolic compound with clear antioxidant activity (6). This compound is widely present in gallnuts, tea leaves, green tea, apples, grapes, strawberries and pineapples (7). Gallic acid has been reported to exert chemopreventive activities through ameliorating oxidative stress and enhancing the antioxidant status (8). In addition to its free radical scavenging abilities and cytoprotective effects, gallic acid has been well reported to act as an anticancer and anti-inflammatory agent (9-12). The present study was designed to analyze the effects of gallic acid against SCI-induced oxidative stress and ion imbalance by evaluating lipid peroxide levels, protein carbonylation, ROS levels, antioxidant status and the enzymatic activities of the $\mathrm{Na}^{+} / \mathrm{K}^{+}, \mathrm{Ca}^{2+}$ and $\mathrm{Mg}^{2+}$ Adenosine triphophatase (ATPase) in Wistar rats.

\section{Materials and methods}

Reagents. Gallic acid (97\%), ketamine, xylazine, Tris- $\mathrm{HCl}$ buffer, 2',7'-dichlorofluorescein diacetate (DCF-DA), phosphate-buffered saline (PBS), Griess, $\mathrm{H}_{2} \mathrm{O}_{2}$, nitrocellulose membranes and Tris-buffered saline with Tween 20 (TBST) were purchased from Sigma-Aldrich (St. Louis, MO, USA). Pierce ECL Western Blotting Substrate was purchased from Life Technologies (Rockford, IL, USA). 
Animals and treatment schedule. All experiments performed in the present study were approved by the Institutional Animal Care Committee at the $117^{\text {th }}$ Hospital of People's Liberation Army (Hangzhou, China). A total of 30 male Wistar rats (160-190g) were obtained from the Animal Center of the Hospital of People's Liberation Army (Beijing, China), were housed under controlled conditions $\left(21 \pm 2^{\circ} \mathrm{C}\right.$; relative humidity, $75 \%$ ) and were fed with a Food and Drug Association-approved diet and water ad libitum. Subsequent to acclimatization, the animals were allocated into the following 3 groups with 10 animals in each: Group I, sham operated animals, laminectomy alone; group II, laminectomy followed by SCI injury; group III, laminectomy followed by SCI and intraperitoneal (i.p.) injection of gallic acid $(10 \mathrm{mg} / \mathrm{kg}$ ) following $1 \mathrm{~h}$ of SCI on day 1 , which continued until day 10 . The laminectomy was performed at the T9 vertebra and the weight drop technique was adopted for the induction of conducive SCI. During this technique, weight $(15 \mathrm{~g})$ was dropped at a height of $2.5 \mathrm{~cm}$ onto the spinal cord for $2 \mathrm{~min}$. Subsequent to the appropriate treatment schedule for the group, the rats were sacrificed with ketamine (75 mg/kg; i.p.) and xylazine (10 mg/kg; i.p.). Blood was collected through cardiac puncture and the serum was separated and stored at $-80^{\circ} \mathrm{C}$. The spinal cord tissues $(2 \mathrm{~cm})$ were obtained. Tissue samples were homogenized using ice-cold Tris- $\mathrm{HCl}$ buffer $(50 \mathrm{mM}, \mathrm{pH} 7.4)$ and centrifuged at $800 \mathrm{x} \mathrm{g}$ for $15 \mathrm{~min}$ at $4^{\circ} \mathrm{C}$. The supernatant was aliquoted and stored at $-20^{\circ} \mathrm{C}$ until used for the measurement of oxidative stress parameters and western blot analysis. Protein estimation was conducted as previously described (13).

Estimation of serum total antioxidant capacity (TAC) and total oxidant status (TOS). The TAC of serum was determined as described previously (14). This method involved quantifying hydroxyl radical formation during reactions between antioxidants in the sample and free radicals. The results are expressed as mmol of Trolox equivalent/1. TOS of serum was determined as described by Erel (15). The results are expressed as $\mu \mathrm{mol} \mathrm{H}_{2} \mathrm{O}_{2}$ equivalent/l. The assay measures oxidation of ferrous ion-o-dianisidine complex to the ferric ion by the oxidants in the serum sample. The formation of the colored complex was measured spectrophotometrically (AquaMate 8000 UV-Vis Spectrophotometer; Thermo Fisher Scientific, Waltham, MA, USA), which is proportional to the quantity of oxidant molecules present. The quantity of oxidants was then compared with that of $\mathrm{H}_{2} \mathrm{O}_{2}$. The results are expressed as $\mu \mathrm{mol} \mathrm{H}_{2} \mathrm{O}_{2}$ equivalent/1.

Determination of tissue oxidative stress and antioxidant status. The tissue homogenate was prepared using ice-cold Tris- $\mathrm{HCl}$ buffer $\left(50 \mathrm{mM}\right.$, pH 7.4) at $4^{\circ} \mathrm{C}$ and the Ultra-Turrax T 25 Basic Homogenizer (IKA-Werke GmbH \& Co., Staufen, Germany). The homogenate was centrifuged at $800 \mathrm{x} \mathrm{g}$ for $15 \mathrm{~min}$. The supernatant was isolated and aliquoted into separate vials and stored at $-20^{\circ} \mathrm{C}$ until further use in various biochemical studies.

\section{Oxidative stress}

Estimation of tissue protein carbonyl content. The protein carbonyls formed were determined as described previously (16). The formation of the Schiffs base during a reaction between the carbonyl group and 2,4-dinitrophenylhydrazone (DNPH) resulted in the formation of carbonyl contents, the levels of which were measured spectrophotometrically (AquaMate $8000 \mathrm{UV}-\mathrm{V}$ is Spectrophotometer) at $370 \mathrm{~nm}$. The results were expressed as nmol carbonyl formed/mg protein.

Estimation of lipid peroxidation. The lipid peroxide levels (thiobarbituric acid reactive substances; TBARS) were determined, as described previously (17). The estimation involved a reaction between malondialdehyde (MDA) and thiobarbituric acid (TBA), which resulted in the formation of TBARS. The pink colored chromogen formed was measured spectrophometrically (AquaMate $8000 \mathrm{UV}-\mathrm{V}$ is Spectrophotometer) at $532 \mathrm{~nm}$. Results were expressed as nmol TBA reactants formed/g wet tissue.

ROS generation. Levels of ROS generated were determined as described by Hashimoto et al (18). The homogenate was incubated with DCF-DA at $37^{\circ} \mathrm{C}$ for $15 \mathrm{~min}$. At the end of the incubation time, centrifugation at 9,000 $\mathrm{x} \mathrm{g}$ was conducted for $15 \mathrm{~min}$. The resultant pellet was re-suspended in PBS and incubated for $60 \mathrm{~min}$ at $37^{\circ} \mathrm{C}$. ROS levels were measured spectrofluorimetrically (AquaMate $8000 \mathrm{UV}-\mathrm{V}$ is Spectrophotometer) at excitation $(485 \mathrm{~nm})$ and emission (528 nm) wavelengths. The results were expressed as the percentage of ROS generation when the control group represented $100 \%$.

Estimation of nitrite levels. The conversion of nitrates to nitrites by nitrate reductase was determined by the addition of Griess reagent. The reaction results in the formation of purple azo compound; therefore, absorbance, which is proportional to the nitrite levels (Nitrate/Nitrite Colorimetric Assay kit; Cayman Chemical Company, Ann Arbor, MI, USA) in the sample, was then measured spectrophotometrically (AquaMate 8000 UV-Vis Spectrophotometer).

\section{Antioxidant status}

Levels of the non-enzymatic antioxidant glutathione (GSH). GSH levels were measured based on the principle reaction between 5,5'-dithiobis(2-nitrobenzoic acid) and reduced GSH. The resultant yellow color formed was measured spectrophotometrically (AquaMate $8000 \mathrm{UV}-\mathrm{Vis}$ Spectrophotometer) at $405 \mathrm{~nm}$. The concentration of GSH was the calculated from standard GSH levels (Glutathione Assay kit; Trevigen, Inc., Gaithersburg, MD, USA).

Superoxide dismutase (SOD) activity. SOD activity was determined as described previously by Sun et al (19). The assay was based on the reduction of nitrobluetetrazolium (NBT). A total of 1 Unit SOD activity = the amount required for $50 \%$ inhibition of NBT reduction. SOD activity is expressed as $\mathrm{U} / \mathrm{mg}$ protein.

Catalase (CAT) activity. CAT activity was determined according to the method described by Aebi (20). The reaction mixture contained tissue homogenate $(50 \mu \mathrm{g})$ and $30 \mathrm{mM}$ $\mathrm{H}_{2} \mathrm{O}_{2}$ in $50 \mathrm{mM}$ PBS, pH 7.0. The activity was estimated by the reduced absorbance of $\mathrm{H}_{2} \mathrm{O}_{2}$ at $240 \mathrm{~nm}$.

GSH-S-transferase (GST) activity. The reaction between 1-chloro-2,4-dinitro benzene (CDNB) and reduced GSH resulted in formation of dinitrophenyl thioether, which was measured at $340 \mathrm{~nm}$, as previously described (21). A total of 1 Unit GST = amount of enzyme producing $1 \mathrm{mmol}$ CDNB-GSH conjugate/min. 
Table I. Effect of gallic acid on TAC and TOS.

\begin{tabular}{lcrr}
\hline Parameter & Group I & Group II & Group III \\
\hline TAC & $4.01 \pm 0.01$ & $2.19 \pm 0.01^{\mathrm{a}}$ & $3.53 \pm 0.01^{\mathrm{b}}$ \\
TOS & $21 \pm 1.9$ & $69 \pm 3.12^{\mathrm{a}}$ & $39 \pm 1.81^{\mathrm{b}}$ \\
\hline
\end{tabular}

Results are given as the mean \pm standard error of the mean for 10 rats in each group. ${ }^{a} \mathrm{P}<0.001$ vs. control and ${ }^{b} \mathrm{P}<0.001 \mathrm{vs}$. SCI group, as determined using a one way analysis of variance followed by Tukey's multiple comparison. TAC, total antioxidant capacity; TOS, total oxidant status; SCI, spinal cord injury; Group I, control; Group II, SCI; Group III, gallic acid + SCI.

A

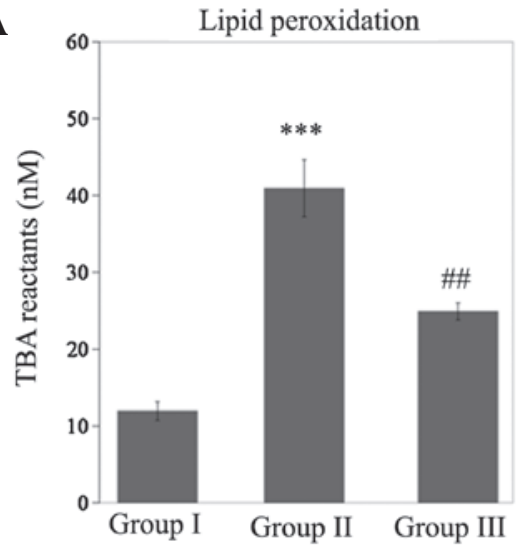

B

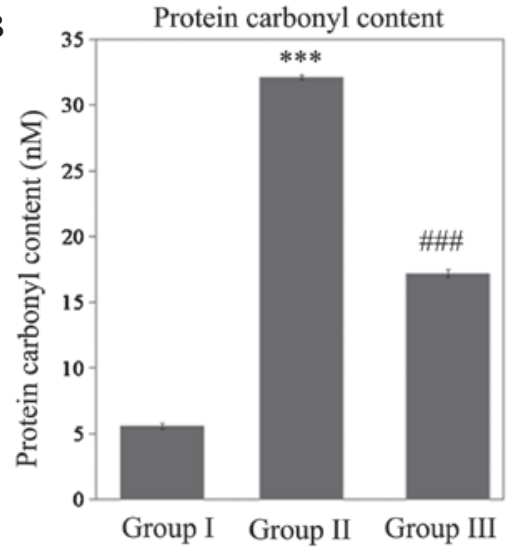

Figure 1. Gallic acid attenuates the increase in lipid peroxidation and protein carbonylation SCI rats. (A) Effect of gallic acid on lipid peroxidation, results are expressed as nmol of TBA reactants formed/mg of protein. (B) Effect of gallic acid of protein carbonylation, results are expressed as nmol of protein carbonyl formed/mg of protein. Results are presented as the mean \pm standard error of the mean for 10 rats in each group; one way analysis of variance followed by Tukey's multiple comparison test. ${ }^{* * *} \mathrm{P}<0.001$ vs. control; ${ }^{\# \#} \mathrm{P}<0.001$ and ${ }^{\# \#} \mathrm{P}<0.01$ vs. SCI group. SCI, spinal cord injury; TBA, thiobarbituric acid; Group I, control; Group II, SCI; Group III, gallic acid + SCI.

GSH peroxidase (GPX) activity. The GPx activity was measured as described by Paglia and Valentine (22). Oxidized GSH is reduced by GSH reductase and NADPH. The oxidation of NADPH to $\mathrm{NADP}^{+}$was measured by the reduction in absorbance at $340 \mathrm{~nm}$. GPx activity is expressed as U/mg protein.

$\mathrm{Na}^{+} / \mathrm{K}^{+}, \mathrm{Ca}^{2+}$ and $\mathrm{Mg}^{2+}$ ATPase enzymatic activities. Tissue $\mathrm{Na}^{+} / \mathrm{K}^{+}$ATPase (Bonting) (23), $\mathrm{Mg}^{2+}$ ATPase (Ohnishi et al) (24)
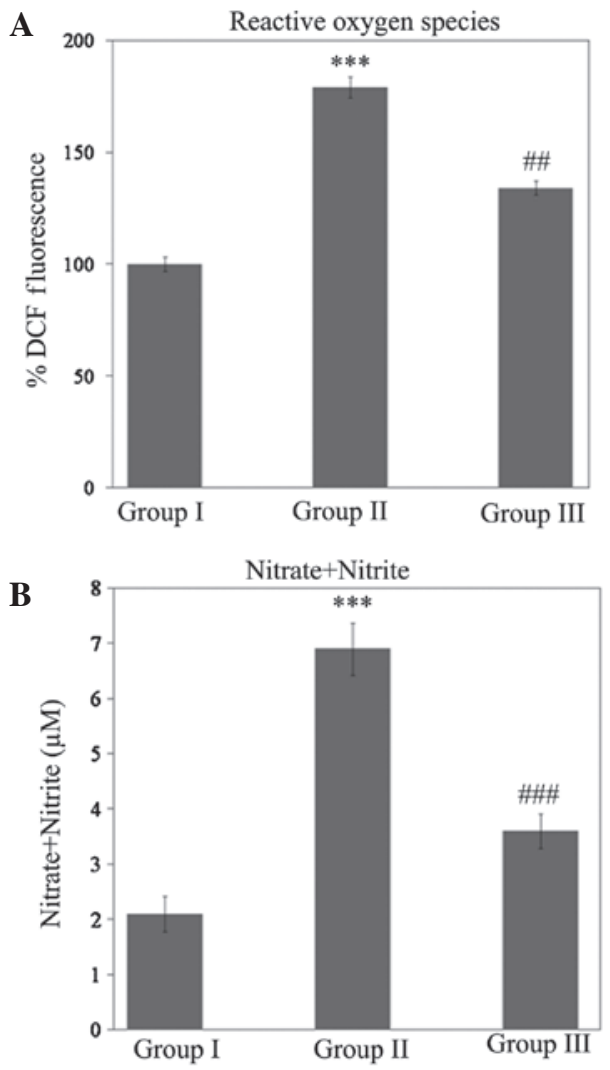

Figure 2. Gallic acid attenuates the increase in ROS and nitrite levels in SCI rats. (A) ROS generation (\% of control) and (B) conversion of nitrate to nitrite ( $\mu \mathrm{M}$ nitrite/mg protein). Results are presented as the mean \pm standard error of the mean for 10 rats in each group; one way analysis of variance followed by Tukey's multiple comparison test. ${ }^{* * *} \mathrm{P}<0.001$ vs. control; ${ }^{\# \#} \mathrm{P}<0.001$ and ${ }^{\# \#} \mathrm{P}<0.01$ vs. SCI group. ROS, reactive oxygen species; SCI, spinal cord injury; Group I, control; Group II, SCI; Group III, gallic acid + SCI; DCF, dichlorofluorescein.

and $\mathrm{Ca}^{2+}$-ATPase (Hjertén and Pan) (25) activities were measured by estimating the inorganic free phosphate. Phosphate reacts with ammonium molybdate to form phosphomolybdate. The reaction between 1-amino, 2-naphthol4-sulfonic acid and phosphomolybdate results in the formation of a blue colored complex measured at a wavelength of $620 \mathrm{~nm}$. Results are expressed as nmole Pi-released/min/mg protein.

Western blot analysis. Tissue homogenates $(50 \mu \mathrm{g})$ from different treatment groups were analyzed for nuclear factor (NF)- $\mathrm{\kappa B}$ and cycloxygenase (COX)-2 expression. Western blot analysis was conducted as described by Towbin et al (26). Briefly, the proteins were separated using 12\% SDS-PAGE (Mini-Protean Tetra Cell systems; Bio-Rad Laboratories, Inc., Hercules, CA, USA) and transferred to nitrocellulose membranes. The blots were blocked with non-fat milk (5\%) at room temperature for $1 \mathrm{~h}$. Subsequent to washing with TBST, the blots were incubated with the following primary antibodies overnight at $4^{\circ} \mathrm{C}$ : Goat polyclonal COX-2 (C-20; sc-1745) and rabbit polyclonal IgG NFKB p65 (C-20; sc-372). Following another wash with TBST, the blots were probed with the goat anti-rabbit COX-2 and rabbit anti-mouse NFKB secondary antibodies for $1 \mathrm{~h}$ at room temperature. Specific primary and secondary antibodies were purchased from Santa Cruz Biotechnology, Inc. (Danvers, TX, USA). Protein expression 


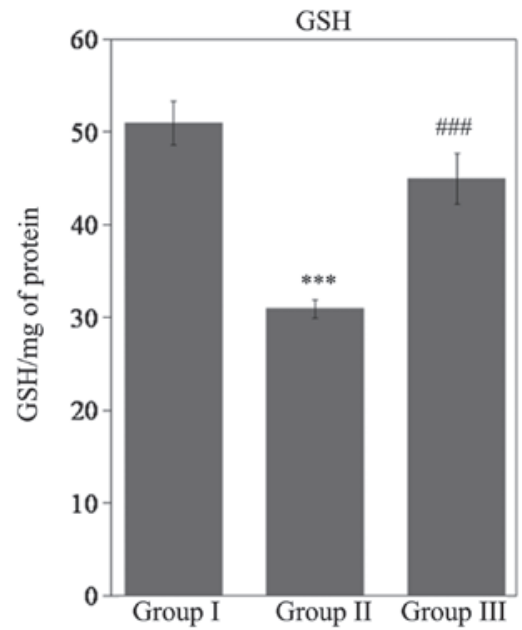

Figure 3. Gallic acid restores GSH levels in SCI rats. Results are expressed as nmol GSH/mg protein. Results are presented as the mean \pm standard error of the mean for 10 rats in each group. ${ }^{* * *} \mathrm{P}<0.001$ vs. control; ${ }^{\# \#} \mathrm{P}<0.001$ vs. SCI group; one way analysis of variance followed by Tukey's multiple comparison test. GSH, glutathione; SCI, spinal cord injury; Group I, control; Group II, SCI; Group III, gallic acid + SCI.

$\mathbf{A}$
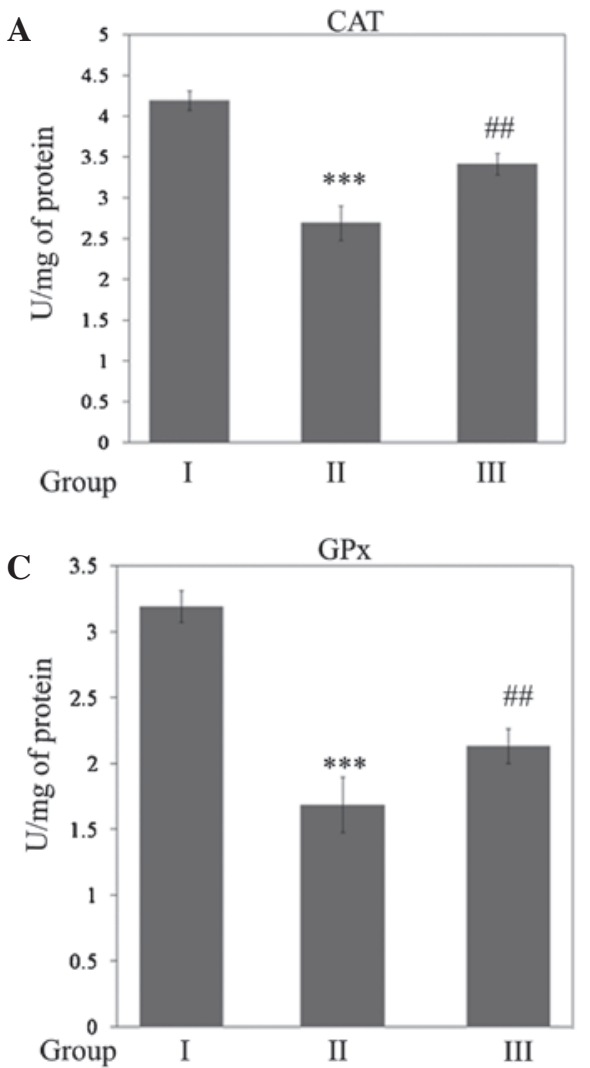

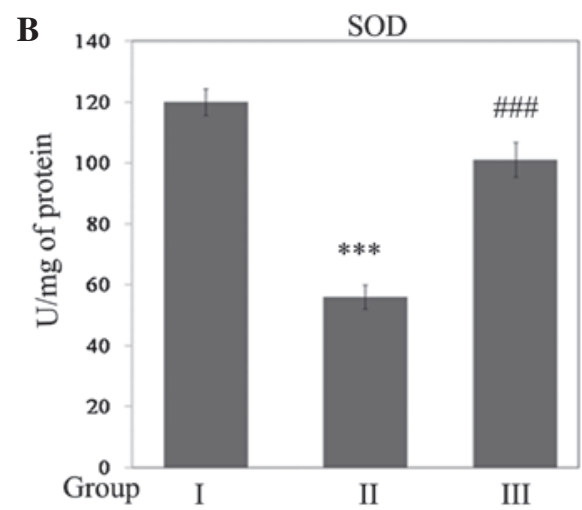

GST

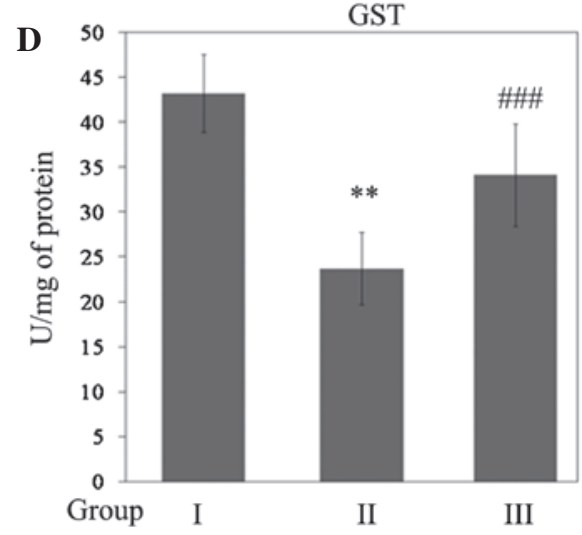

Figure 4. Gallic acid restores antioxidant status in SCI rats. (A) CAT activity; (B) SOD activity; (C) GPx activity; and (D) GST activity. Results are expressed as $\mathrm{U} / \mathrm{mg}$ protein and presented as the mean \pm standard error of the mean for 10 rats in each group. ${ }^{* * *} \mathrm{P}<0.001$ and ${ }^{* *} \mathrm{P}<0.01$ vs. control; ${ }^{\# \# \#} \mathrm{P}<0.001$ and ${ }^{\# \#} \mathrm{P}<0.01$ vs. SCI group; one way analysis of variance followed by Tukey's multiple comparison test. SCI, spinal cord injury; CAT, catalase; SOD, superoxide dismuatase; GPx, glutathione peroxidase; GST, glutathone-S-transferase; Group I, control; Group II, SCI; Group III, gallic acid + SCI.

levels were visualized using the Enhanced Chemiluminescence Detection System and the band intensities were measured using ImageJ software, version 1.41 (http://imagej.nih.gov/ij/).

Statistical analysis. Data were analyzed using a one-way analysis of variance followed by Tukey's multiple comparison test. All biochemical experiments were performed in triplicate to ensure reproducibility. SPSS software, version 22.0 (IBM SPSS, Armonk, NY, USA) was used for the statistical analysis.

\section{Results}

Effect of gallic acid on serum TAC and TOS levels. As shown in Table I, the results of the present study demonstrated a statisti- 


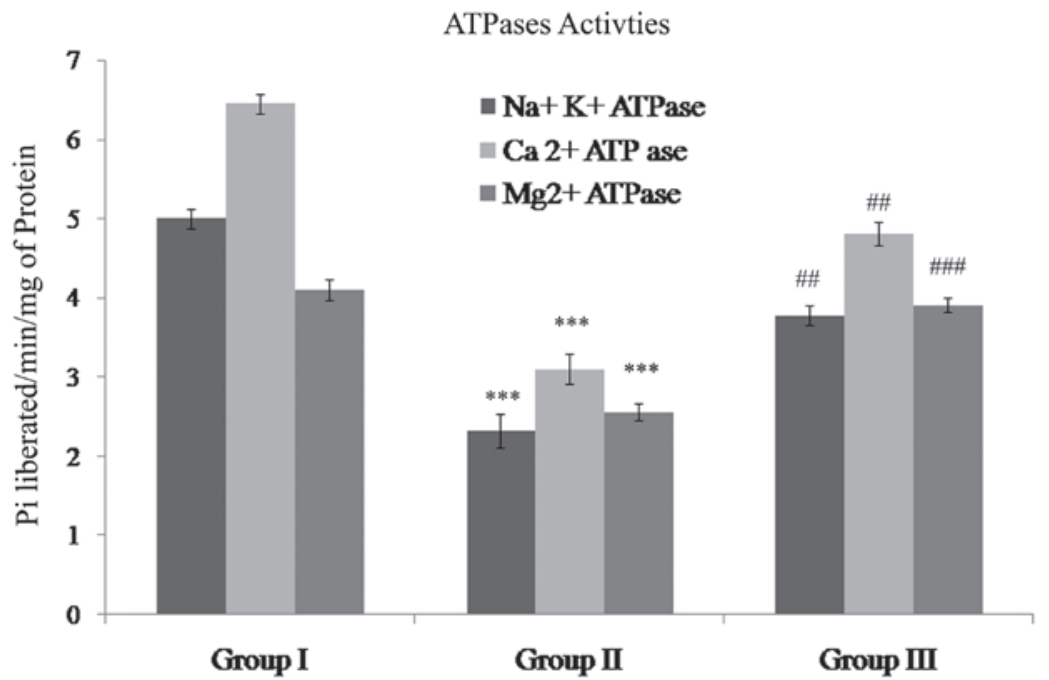

Figure 5. Gallic acid modulates ATPase enzyme activities in SCI rats. Activities of $\mathrm{Na}^{+} \mathrm{K}^{+}, \mathrm{Ca}^{2+}$ and $\mathrm{Mg}^{2+}$ ATPase were determined following SCI in rats. Results are expressed as free inorganic phosphate $/ \mathrm{min} / \mathrm{mg}$ of protein. Results are presented as the mean \pm standard error of the mean for 10 rats in each group. ${ }^{* * * *} \mathrm{P}<0.001$ vs. control; ${ }^{\# \#} \mathrm{P}<0.01$ vs. SCI group; ${ }^{\# \# \#} \mathrm{P}<0.001$ vs. SCI group; one way analysis of variance followed by Tukey's multiple comparison test. SCI, spinal cord injury; Group I, control; Group II, SCI; Group III, gallic acid + SCI.

A

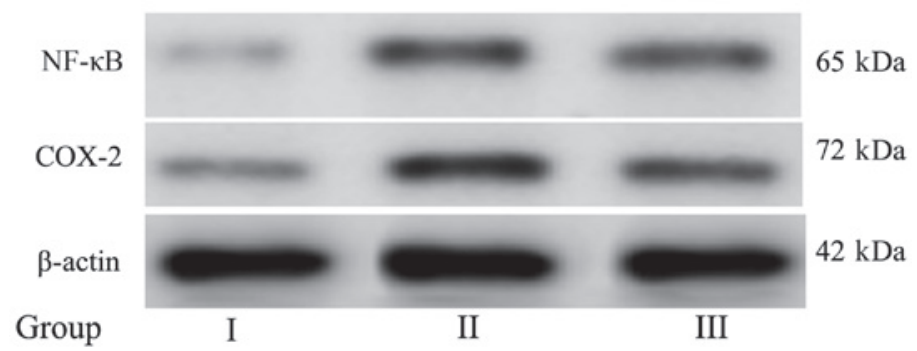

B

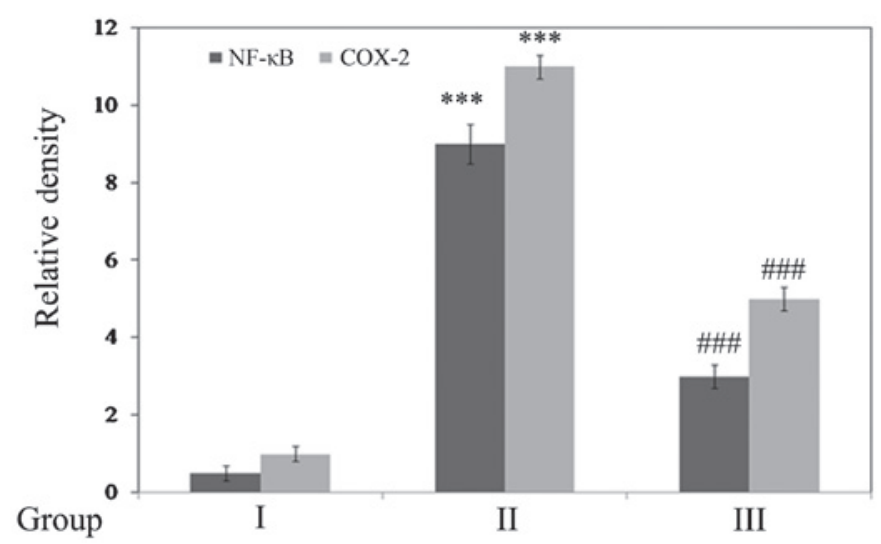

Figure 6. Gallic acid inhibits inflammatory protein expression (NF-kb and COX-2) in SCI. (A) Western blot analysis of NF-kb and COX-2 expression. (B) Densitometric analysis of NF-kb and COX-2 expressions. Statistical analyses were conducted using the Student's t-test. Results are expressed as the mean \pm standard error of the mean. ${ }^{* * *} \mathrm{P}<0.001$ vs. control rats; ${ }^{\# \# \#} \mathrm{P}<0.001$ vs. SCI group. NF-kb; nuclear factor-kb; COX-2; cyclooxygenase-2; Group I, control; Group II, SCI; Group III, gallic acid + SCI.

cally significant increase in TOS levels $(\mathrm{P}<0.001)$ in rats with SCI when compared with control rats. By contrast, the levels of TAC were significantly reduced $(\mathrm{P}<0.001)$ in $\mathrm{SCI}$ rats when compared with the control. Treatment with gallic acid resulted in a significant reduction in TOS levels $(\mathrm{P}<0.001)$ with an increase in TAC levels $(\mathrm{P}<0.001)$ when compared with SCI rats (Table I).

Gallic acid ameliorates SCI-induced oxidative stress in Wistar rats. Significant increases in lipid peroxide levels $(\mathrm{P}<0.001)$ and protein carbonyl content $(\mathrm{P}<0.001)$ were observed in rats with SCI injury, when compared with the control (Fig. 1). In addition, there was a significant reduction $(\mathrm{P}<0.01)$ in these levels when compared with SCI rats. This indicated that treatment with gallic acid attenuated the rise in lipid peroxidation $(\mathrm{P}<0.01)$ and protein carbonylation $(\mathrm{P}<0.001)$. As shown in Fig. 2, a significant increase $(\mathrm{P}<0.001)$ in ROS and nitrite levels during SCI injury was ameliorated $(\mathrm{P}<0.01$ and $\mathrm{P}<0.001$ for ROS and nitrite levels, respectively) during treatment with gallic acid (Fig. 2). 
Gallic acid enhances antioxidant status and prevents SCI in Wistar rats. Activity levels of GSH, CAT, SOD, GPx $(\mathrm{P}<0.001)$ and GST $(\mathrm{P}<0.01)$ were significantly reduced during SCI in Wistar rats (Figs. 3 and 4). However, rats treated with gallic acid followed by SCI injury exhibited a statistically significant increase $(\mathrm{P}<0.001)$ when compared with SCI rats. In response to this decline in antioxidant status, the levels of GSH $(\mathrm{P}<0.001)$, SOD $(\mathrm{P}<0.001)$, CAT $(\mathrm{P}<0.01)$, GPx $(\mathrm{P}<0.01)$ and GST $(\mathrm{P}<0.001)$ were significantly increased in rats treated with gallic acid followed by SCI when compared with SCI rats (Fig. 4).

Gallic acid restored the activity of the $\mathrm{Na}^{+} / \mathrm{K}^{+}, \mathrm{Ca}^{2+}$ and $\mathrm{Mg}^{2+}$ ATPases during SCI. The activities of the $\mathrm{Na}^{+} / \mathrm{K}^{+}, \mathrm{Ca}^{2+}$ and $\mathrm{Mg}^{2+}$ ATPases in SCI were identified to be significantly reduced $(\mathrm{P}<0.001)$ when compared with control rats. Treatment with gallic acid showed statistically significant increases in the activities of the $\mathrm{Na}^{+} / \mathrm{K}^{+}(\mathrm{P}<0.01), \mathrm{Ca}^{2+}(\mathrm{P}<0.01)$ and $\mathrm{Mg}^{2+}$ $(\mathrm{P}<0.001)$ ATPases compared with those in the SCI group (Fig. 5).

Gallic acid inhibits SCI-induced inflammatory responses. The expression levels of the inflammatory markers $\mathrm{NF}-\kappa \mathrm{B}$ and COX-2 were determined. Densitometric analysis demonstrated that expression of these markers was significantly upregulated $(\mathrm{P}<0.001)$ in SCI rats compared with the control. In addition, treatment with gallic acid significantly downregulated $(\mathrm{P}<0.001)$ the expression of $\mathrm{NF}-\kappa \mathrm{B}$ and $\mathrm{COX}-2$ when compared with SCI rats (Fig. 6).

\section{Discussion}

The key mediator of persistent SCI is secondary injury, which occurs as a result of physical and conducive damage to the spinal cord. Within minutes to hours of the initiation of primary mechanical injury, the secondary effect is initiated and the adverse effects which occur are proportional to that of the primary injury (5). The degenerative events which occur as a result of secondary injury are mediated through the activation of various signaling cascades, disturbances in ion homeostasis and the production of ROS. Oxidative stress is key in the production of tissue damage (27-30). Thus, spinal cord damage and subsequent loss of neurological function occurs via apoptosis/necrosis. As secondary damage has been reported to be mediated by oxidative stress and its downstream events, pharmacological intervention with free radical scavengers is suggested to be able to efficiently block this oxidation-induced tissue damage. The present study demonstrated promising results, identifying that gallic acid, a potential antioxidant compound, prevented SCI via pharmacological intervention.

The measurement of TAC and TOS is a widely used marker for the evaluation of the total oxidative stress status during injury. The current study observed that treatment with the antioxidant gallic acid was able to significantly prevent the total oxidant levels in serum and the associated increase in total antioxidant capacity during SCI. Previous studies have reported that free radical-mediated loss of neurological function is a key event in SCI $(31,32)$. Thus, the present study evaluated various markers of oxidative stress, which resulted in the observation that SCI led to a significant rise in ROS generation. The reaction between various reactive oxygen and nitrogen species formed during stress conditions results in the formation of peroxynitrite radicals. Reports suggest that these peroxy radicals have critical roles in the initiation of mechanisms mediating lipid peroxidation (31).

Lipid peroxidation is a complex process resulting in the damage of lipids, which alters the cellular membranes and ultimately cellular function. These oxidative alterations in the membrane lipids are irreversible. Lipid peroxidation and the resulting oxidative damage to lipids occurs as a result of the insertion of an oxygen molecule through enzymatic or non-enzymatic mechanisms (33). The impact of lipid peroxidation leads to alterations in membrane fluidity, permeability, in addition to the loss of cell-cell contacts. Alterations to the membrane lipids result in an aggravation of oxidative stress and pro-inflammatory mechanisms (34). The toxic byproducts of lipid peroxidation have been reported to mediate carcinogenic and mutagenic effects (35). Thus, complex interactions between lipid peroxides, ROS and RNS molecules are suggested to result in the loss of neurological function. In addition, these peroxides react with specific amino acids in proteins such as arginine, cysteine and lysine to form carbonylation proteins, resulting in the loss of protein function (33). Various studies have demonstrated that lipid peroxidation serves a crucial role in SCI $(32,36,37)$. The present study identified that tissue levels of ROS, lipid peroxides, protein carbonylation products and nitrites were significantly increased during SCI, and that these effects were ameliorated by gallic acid treatment, which resulted in the decreased expression of these oxidative stress markers.

Normal cellular functions are controlled by cell through maintaining the oxidant and antioxidant balance. However, in cases of extreme oxidative stress, cells lose control over this balance, which results in increased oxidative stress with depletion of the antioxidant status (4). Several non-enzymatic and enzymatic antioxidants are involved in the regulation of oxidative stress.GSH is an endogenous antioxidant, which commonly acts as a first line of defense against stress conditions. The reaction between ROS and GSH during stress oxidizes and inactivates GSH (38); oxidative damage overwhelms cellular antioxidant levels, which results in tissue injury. In addition to GSH, cells also contain various enzymatic antioxidants, including CAT, SOD, GPx and GST, which protect against cellular damage. The present study observed a significant reduction in the activities of the antioxidant status during SCI. However, gallic acid treatment enhanced antioxidant levels through increasing the activities of non-enzymatic and enzymatic antioxidant activities. Kim et al (39) demonstrated that curcumin treatment enhanced the plasma antioxidant status of cells and reduced lipid peroxidation levels during in acute SCI. Enhanced GSH levels and inhibition of MDA levels previously were reported in rats treated with oleuropein during SCI (40). The protective effects of gallic acid mediated by the upregulation of antioxidant mechanisms have been previously reported in various oxidative stress conditions (41-43).

Oxidative stress is closely associated with the activation of inflammatory genes, as ROS is a key mediator in these events (44). Initiation of inflammation largely occurs with activation of $\mathrm{NF}-\kappa \mathrm{B}$ followed by downstream genes, including those for COX-2, inducible nitric oxide synthase and various 
interleukins and cytokines (45). The present study demonstrated the significant upregulation of inflammatory proteins, such as $\mathrm{NF}-\kappa \mathrm{B}$ and $\mathrm{COX}-2$, during SCI injury in rats; in addition, gallic acid exhibited anti-inflammatory effects by downregulating these proteins. These results are consistent with previous studies, where SCI induced inflammatory mechanisms via regulation of COX-2, nitric oxide levels and the release of prostaglandins $(46,47)$. Similar protection by gallic acid through inhibition of the $\mathrm{NF}-\kappa \mathrm{B}$ protein was demonstrated in the prevention of cancer (48) and lipopolysaccharide-induced inflammation (49).

Previous studies have identified that SCI resulted in the deregulation of ion homeostasis, including calcium ion influx and subsequent calcium overload $(50,51)$. Calcium overload results in the activation of various biochemical cascades and signaling mechanisms, which have been demonstrated to lead to the adverse effects of oxidative stress and inflammatory responses, resulting in tissue damage and loss of normal cell function (50). Previous studies have also indicated that early events in SCI induce depolarization of the membranes, which results in the opening of various ion channels (52). These ion concentrations are maintained by membrane bound ATPase enzymes; however, as these enzymes are inactivated under oxidative stress, alterations in lipid composition occur (53). The present study observed extensive oxidative stress during SCI; therefore, it was investigated whether SCI results in any alterations in the activity of ATPase enzymes. This was achieved by evaluating the activities of the $\mathrm{Na}^{+} / \mathrm{K}^{+}, \mathrm{Ca}^{2+}$ and $\mathrm{Mg}^{2+}$ ATPases during SCI. The results demonstrated a significant reduction in ATPase activity; in addition, treatment with gallic acid restored the enzyme activities and maintained normal ion homeostasis. This was consistent with a previous study by Vijaya Padma et al (54), which identified that gallic acid treatment significantly maintained the antioxidant status and ATPase activity, thereby preventing cardiotoxicty in Wistar rats.

In conclusion, the results of the present study provided evidence that pharmacological intervention with gallic acid prevented and restored SCI-induced oxidative stress and ion homeostasis.

\section{References}

1. Amar AP and Levy ML: Pathogenesis and pharmacological strategies for mitigating secondary damage in acute spinal cord injury. Neurosurgery 44: 1027-1039, 1999.

2. Hall ED: The role of oxygen radicals in traumatic injury: clinical implications. J Emerg Med 11 (Suppl 1): 31-36, 1993.

3. Hall ED: Lipid antioxidants in acute central nervous system injury. Ann Emerg Med 22: 1022-1027, 1993.

4. Hall ED: Antioxidant therapies for acute spinal cord injury. Neurotherapeutics 8: 152-167, 2011.

5. Li L, Ng TB, Gao W, Li W, Fu M, Niu SM, Zhao L, Chen RR and Liu F: Antioxidant activity of gallic acid from rose flowers in senescence accelerated mice. Life Sci 77: 230-240, 2005.

6. Ng TB, He JS, Niu SM, Zhao L, Pi ZF, Shao W and Liu F: A gallic acid derivative and polysaccharides with antioxidative activity from rose (Rosa rugosa) flowers. J Pharm Pharmacol 56: 537-545, 2004

7. Giftson JS, Jayanthi S and Nalini N: Chemopreventive efficacy of gallic acid, an antioxidant and anticarcinogenic polyphenol, against 1,2-dimethyl hydrazine induced rat colon carcinogenesis. Invest New Drugs 28: 251-259, 2010.

8. Kroes BH, van den Berg AJ, Quarles van Ufford HC, van Dijk H and Labadie RP: Anti-inflammatory activity of gallic acid. Planta Med 58: 499-504, 1992.
9. Pellegrina CD, Padovani G, Mainente F, Zoccatelli G, Bissoli G, Mosconi S, Veneri G, Peruffo A, Andrighetto G, Rizzi C and Chignola R: Anti-tumour potential of a gallic acid-containing phenolic fraction from Oenothera biennis. Cancer Lett 226: 17-25, 2005.

10. Hsu CL, Lo WH and Yen GC: Gallic acid induces apoptosis in 3T3-1 pre-adipocytes via a Fas- and mitochondrial-mediated pathway. J Agric Food Chem 55: 7359-7365, 2007.

11. Inoue M, Suzuki R, Sakaguchi N, Li Z, Takeda T, Ogihara Y, Jiang BY and Chen Y: Selective induction of cell death in cancer cells by gallic acid. Biol Pharm Bull 18: 1526-1530, 1995.

12. Patel SS and Goyal RK: Cardioprotective effects of gallic acid in diabetes-induced myocardial dysfunction in rats. Pharmacognosy Res 3: 239-245, 2011.

13. Lowry OH, Rosebrough NJ, Farr AL and Randall RJ: Protein measurement with the Folin phenol reagent. J Biol Chem 193: 265-275, 1951.

14. Erel O: A novel automated method to measure total antioxidant response against potent free radical reactions. Clin Biochem 37: 112-119, 2004.

15. Erel O: A new automated colorimetric method for measuring total oxidant status. Clin Biochem 38: 1103-1111, 2005.

16. Levine RL, Garland D, Oliver CN, Amici A, Climent I, Lenz AG, Ahn BW, Shaltiel S and Stantman ER: Determination of carbonyl content in oxidatively modified proteins. Methods Enzymol 186: 464-478, 1990.

17. Esterbauer $\mathrm{H}$ and Cheeseman $\mathrm{KH}$ : Determination of aldehydic lipid peroxidation products: malonaldehyde and 4-hydroxynonenal. Methods Enzymol 186: 407-421, 1990.

18. Hashimoto M, Tanabe Y, Fujii Y, Kikuta T, Shibata H and Shido O: Chronic administration of docosahexaenoic acid ameliorates the impairment of spatial cognition learning ability in amyloid beta-infused rats. J Nutr 135: 549-555, 2005.

19. Sun Y, Oberley LW and Li Y: A simple method for clinical assay of superoxide dismutase. Clin Chem 34: 497-500, 1988.

20. Aebi H: Catalase. In: Methods of Enzymatic Analysis. Bergmeyer U (ed). Academic Press, New York, pp673-677, 1974.

21. Habig WH, Pabst MJ and Jakoby WB: Glutathione S-transferases. The first enzymatic step in mercapturic acid formation. J Biol Chem 249: 7130-7139, 1974.

22. Paglia DE and Valentine WN: Studies on the quantitative and qualitative characterisation of erythrocyte glutathione peroxidase. J Lab Clin Med 70: 158-169, 1967.

23. Bonting SL: Sodium-potassium activated adenosine triphosphatase and cation transport. In: Membranes and Ion Transport. Bittar EE (ed). Wiley-Interscience, London, pp257-263, 1970.

24. Ohnishi T, Suzuki T, Suzuki Y and Ozawa K: A comparative study of plasma membrane $\mathrm{Mg} 2+$-ATPase activities in normal, regenerating and malignant cells. Biochim Biophys Acta 684: 67-74, 1982 .

25. Hjertén S and Pan H: Purification and characterization of two forms of a low-affinity Ca2+-ATPase from erythrocyte membranes. Biochim Biophys Acta 728: 281-288, 1983.

26. Towbin H, Staehelin T and Gordon J: Electrophoretic transfer of proteins from polyacrylamide gels to nitrocellulose sheets: procedure and some applications. Proc Natl Acad Sci USA 76: 4350-4354, 1979.

27. Hall ED and Braughler JM: Central nervous system trauma and stroke. II. Physiological and pharmacological evidence for involvement of oxygen radicals and lipid peroxidation. Free Radic Biol Med 6: 303-313, 1989.

28. Tator $\mathrm{CH}$ and Fehlings MG: Review of the secondary injury theory of acute spinal cord trauma with emphasis on vascular mechanisms. J Neurosurg 75: 15-26, 1991.

29. Faden AI: Therapeutic approaches to spinal cord injury. Adv Neurol 72: 377-386, 1997.

30. Faden AI and Salzman S: Pharmacological strategies in CNS trauma. Trends Pharmacol Sci 13: 29-35, 1992.

31. Hall ED and Braughler JM: Free radicals in CNS injury. Res Publ Assoc Res Nerv Ment Dis 71:81-105, 1993.

32. Koc RK, Akdemir H, Karakücük EI, Oktem IS and Menkü A: Effect of methylprednisolone, tirilazad mesylate and vitamin E on lipid peroxidation after experimental spinal cord injury. Spinal Cord 37: 29-32, 1999.

33. Halliwell B and Gutteridge JM (eds): Oxidative stress. In: Free Radicals in Biology and Medicine. 3rd edition. Oxford University Press, New York, pp246-350, 1999.

34. Greenberg ME, Li XM, Gugiu BG, Gu X, Qin J, Salomon RG and Hazen SL: The lipid Whisker model of the structure of oxidized cell membranes. J Biol Chem 283:2385-2396, 2008. 
35. West JD and Marnett LJ: Endogenous reactive intermediates as modulators of cell signaling and cell death. Chem Res Toxicol 19: 173-194, 2006.

36. Christie SD, Comeau B, Myers T, Sadi D, Purdy M and Mendez I: Duration of lipid peroxidation after acute spinal cord injury in rats and the effect of methylprednisolone. Neurosurg Focus 25: E5, 2008

37. Diaz-Ruiz A, Rios C, Duarte I, Correa D, Guizar-Sahagun G, Grijalva I, Madrazo I and Ibarra A: Lipid peroxidation inhibition in spinal cord injury: cyclosporin-A vs. methylprednisolone. Neuroreport 11: 1765-1767, 2000.

38. Price A, Lucas PW and Lea PJ: Age dependent damage and glutathione metabolism in ozone fumigated barley: a leaf section approach. J Exp Bot 41: 1309-1317, 1990.

39. Kim KT, Kim MJ, Cho DC, Park SH, Hwang JH, Sung JK, Cho HJ and Jeon Y: The neuroprotective effect of treatment with curcumin in acute spinal cord injury: laboratory investigation. Neurol Med Chir (Tokyo) 54: 387-394, 2014.

40. Khalatbary AR and Ahmadvand H: Neuroprotective effect of oleuropein following spinal cord injury in rats. Neurol Res 34: 44-51, 2012.

41. Nabavi SF, Habtemariam S, Jafari M, Sureda A and Nabavi SM: Protective role of gallic acid on sodium fluoride induced oxidative stress in rat brain. Bull Environ Contam Toxicol 89: 73-77, 2012.

42. Ramkumar K, Vijayakumar R, Vanitha P, Suganya N, Manjula C, Rajaguru P, Sivasubramanian S and Gunasekaran P: Protective effect of gallic acid on alloxan-induced oxidative stress and osmotic fragility in rats. Hum Exp Toxicol 33: 638-649, 2013.

43. Mansouri MT, Farbood Y, Sameri MJ, Sarkaki A, Naghizadeh B and Rafeirad M: Neuroprotective effects of oral gallic acid against oxidative stress induced by 6-hydroxydopamine in rats. Food Chem 138: 1028-1033, 2013.

44. Kurtoglu T, Basoglu H, Ozkisacik EA, Cetin NK, Tataroglu C, Yenisey $\mathrm{C}$ and Discigil B: Effects of cilostazol on oxidative stress, systemic cytokine release, and spinal cord injury in a rat model of transient aortic occlusion. Ann Vasc Surg 28: 479-488, 2014.

45. Carroll JE, Hess DC, Howard EF and Hill WD: Is nuclear factor-kappaB a good treatment target in brain ischemia/reperfusion injury? Neuroreport 11: R1-4, 2000.
46. Maihöfner C, Schlötzer-Schrehardt U, Gühring H, Zeilhofer HU, Naumann GO, Pahl A, Mardin C, Tamm ER and Brune K: Expression of cyclooxygenase-1 and -2 in normal and glaucomatous human eyes. Invest Ophthalmol Vis Sci 42: 2616-2624, 2001.

47. Yamamoto $\mathrm{T}$ and Nozaki-Taguchi N: Analysis of the effects of cyclooxygenase (COX)-1 and COX-2 in spinal nociceptive transmission using indomethacin, a non-selective COX inhibitor and NS-398, a COX-2 selective inhibitor. Brain Res 739: 104-110, 1996.

48. Morais MC, Luqman S, Kondratyuk TP, Petronio MS, Regasini LO, Silva DH, Bolzani VS, Soares CP and Pezzuto JM: Suppression of TNF- $\alpha$ induced NFKB activity by gallic acid and its semi-synthetic esters: possible role in cancer chemoprevention. Nat Prod Res 24: 1758-1765, 2010.

49. Choi KC, Lee YH, Jung MG, Kwon SH, Kim MJ, Jun WJ, Lee J, Lee JM and Yoon HG: Gallic acid suppresses lipopolysaccharide-induced nuclear factor-kappaB signaling by preventing RelA acetylation in A549 lung cancer cells. Mol Cancer Res 7: 2011-2021, 2009.

50. Bains $\mathrm{M}$ and Hall ED: Antioxidant therapies in traumatic brain and spinal cord injury. Biochim Biophys Acta 1822: 675-684, 2012.

51. Fleming JC, Norenberg MD, Ramsay DA, Dekaban GA, Marcillo AE, Saenz AD, Pasquale-Styles M, Dietrich WD and Weaver LC: The cellular inflammatory response in human spinal cords after injury. Brain 129: 3249-3269, 2006.

52. Oyinbo CA: Secondary injury mechanisms in traumatic spinal cord injury: A nugget of this multiply cascade. Acta Neurobiol Exp (Wars) 71: 281-299, 2011.

53. Carageorgiou H, Tzotzes V, Pantos C, Mourouzis C, Zarros A and Tsakiris S: In vivo and in vitro effects of cadmium on adult rat brain total antioxidant status, acetylcholinesterase, $(\mathrm{Na}+, \mathrm{K}+)$-ATPase and $\mathrm{Mg} 2+-\mathrm{ATPase}$ activities: protection by L-cysteine. Basic Clin Pharmacol Toxicol 94: 112-118, 2004.

54. Vijaya Padma V, Poornima P, Prakash C and Bhavani R: Oral treatment with gallic acid and quercetin alleviates lindane-induced cardiotoxicity in rats. Can J Physiol Pharmacol 91: 134-140, 2013. 